\title{
Growth analyses of tomato genotypes grown under low energy conditions
}

\author{
M. NIEUWHOF, F. GARRETSEN \& J. C. VAN OEVEREN \\ Centre for Plant Breeding and Reproduction Research (CPRO-DLO), P.O. Box 16, NL 6700 \\ AA Wageningen, Netherlands
}

Received: 25 February 1991; accepted: 27 May 1991

\begin{abstract}
Growth analyses were carried out with young plants of a series of tomato genotypes grown at three night temperatures (NT), under an $8 \mathrm{~h}$ photoperiod and a low light intensity. Significant genotypic differences for RGR, NAR, LAR, SLA and LWR occurred. For these characters, significant but small genotype $\times$ NT interactions were also found. RGR, LAR and SLA increased and LWR decreased with higher NT, while there was no distinct NT effect on NAR. Between NAR and LAR, and NAR and SLA a strong negative correlation was observed, and between LAR and SLA a positive correlation. Plant weight was also strongly influenced by seed size.
\end{abstract}

Keywords: Lycopersicon esculentum, tomato, breeding, genotypic variation, growth analysis, low energy conditions, night temperature, seed size

Abbreviations and definitions: $\mathrm{LA}=$ leaf area, $\mathrm{W}=$ dry plant weight, $\mathrm{RGR}=$ relative growth rate (increase in $\mathrm{W}$ per unit of time and unit of $\mathrm{W}$ ), NAR = net assimilation rate (increase in W per unit of time and unit of LA), LAR = leaf area ratio (leaf area per unit of W), SLA = specific leaf area (leaf area per unit of dry leaf weight), LWR = leaf weight ratio (leaf weight per unit of $\mathrm{W}$ ), MANOVA $=$ multivariate analysis of variance, $D T=$ day temperature, $\mathrm{NT}=$ night temperature.

\section{Introduction}

In the Netherlands, tomato crops are grown in heated glasshouses. To save energy costs, research has been carried out on the prospects of breeding cultivars with low temperature requirements. To investigate genotypic adaption of tomato to low energy conditions, growth analyses were carried out with young plants of tomato cultivars and lines with varying performance under low energy conditions (Nieuwhof et al., 1987). These genotypes were grown in growth rooms under low light intensity at three NTs.

In a preliminary experiment (Exp. 1), significant genotypic differences and genotype $\times$ NT interactions were found (Smeets \& Garretsen, 1986). However, since the genotypes of Exp. 1 were distributed over three subexperiments, sown at different 
dates, the experimental design was not optimal to compare genotypes included in different subexperiments. This paper compares the results with those of a further experiment (Exp. 2) in which all the genotypes were sown at the same date.

\section{Materials and methods}

Exp. 2 was carried out with 15 genotypes, 14 of which were the same as in Exp. 1 (Smeets \& Garretsen, 1986). 'Sonatine' was again used as control cultivar. Seeds of each genotype were fractionated and per genotype the fraction with the highest frequency was used for sowing (Table 2).

On 4 February 1985 seeds were sown in seed trays arranged to four randomized blocks in a growth room in the dark at $25^{\circ} \mathrm{C}$. Four days after sowing seeds emerged and temperature was lowered to $19 / 14{ }^{\circ} \mathrm{C}$ DT/NT, and light from Philips $400 \mathrm{~W}$ HPI-T high-pressure metal halid lamps $\left(24 \mathrm{~W} \mathrm{~m}^{-2}\right.$ visible radiation at the top of the plants) was given for eight hours per day. On 14 February, 21 plants per plot were potted in 1.11 pots (one plant per pot), distributed over three growth rooms at $19 / 14{ }^{\circ} \mathrm{C}$ DT/NT and arranged according to the same design as used for sowing. At this date dry weight of 10 seedlings per plot was determined. On 6 March, in two rooms NT was lowered to 10 and $6{ }^{\circ} \mathrm{C}$, respectively.

Plants were harvested at five dates, the first being on 6 March and the last from 16 to 23 April. At the first harvest, two plants per plot were harvested and at later harvests one plant per plot. Mean harvest dates $\overline{\mathrm{t}}$ at 6,10 and $14{ }^{\circ} \mathrm{C}$ NT were Day $55.4,52.6$ and 49.8, respectively. At the last harvest, plants just entered the generative stage or were still vegetative. Dry weights of stems and leaves were determined, after drying at $105^{\circ} \mathrm{C}$ for 12 hours in a ventilated oven and leaf area was measured with a LI-COR Area Meter, Model LI-3100.

Growth curves for $\ln$ dry plant weight, $\ln$ leaf area and $\ln$ dry leaf weight per plant were calculated assuming a quadratic relationship with time. From these curves, functions of time for RGR, NAR, LAR, SLA and LWR were derived. The parameters for level, slope and curvature of the curves were analysed using a MANOVA procedure (Keuls \& Garretsen, 1982; Garretsen \& Keuls, 1986).

\section{Results}

In Exp. 2, $\ln W$ at mean harvest time $\bar{t}$ was 14 percent higher than in Exp. 1 (Smeets \& Garretsen, 1986), while mean values of the growth components were about similar (Table 1). For all components significant genotypic differences occurred (Table 2). Genotypic variation for $\ln W$, RGR and LWR was rather small, and for NAR, LAR and SLA considerably higher. The genotypes showed essentially the same growth pattern in both experiments.

In both experiments, RGR, LAR and SLA increased with higher NTs, but LWR decreased (Table 3). No significant effects of NT were seen on NAR.

RGR, LAR and LWR always decreased with time. In Exp. 1 at $14{ }^{\circ} \mathrm{C}$ NT no clear effects of time on NAR were present, and at 6 and $10^{\circ} \mathrm{C}$ NT a decrease was preceded by an increase. In Exp. 2, NAR decreased with time in all cases. Decreases of 
Table 1. Genotypic variation for seed weight, and mean values at average harvest time $\bar{t}$ for $\ln W$ and growth components of 15 tomato genotypes in two experiments. Weight in mg, leaf area in $\mathrm{cm}^{2}$ and time in days. Means of three NTs.

\begin{tabular}{|c|c|c|c|c|c|c|c|c|c|c|c|c|c|c|}
\hline \multirow[b]{2}{*}{ Exp. } & \multicolumn{2}{|c|}{$\begin{array}{l}10^{2} \text { Seed } \\
\text { weight }\end{array}$} & \multicolumn{2}{|c|}{$10^{2} \ln W$} & \multicolumn{2}{|c|}{$10^{3}$ RGR } & \multicolumn{2}{|c|}{$10^{3} \mathrm{NAR}$} & \multicolumn{2}{|c|}{$10^{2} \mathrm{LAR}$} & \multicolumn{2}{|c|}{$10^{2}$ SLA } & \multicolumn{2}{|c|}{$10^{2} \mathrm{LWR}$} \\
\hline & 1 & 2 & 1 & 2 & 1 & 2 & 1 & 2 & 1 & 2 & 1 & 2 & 1 & 2 \\
\hline $\begin{array}{l}\text { Genotype with } \\
\text { lowest value }\end{array}$ & 160 & 144 & 539 & 629 & 99 & 98 & 185 & 192 & 41 & 38 & 59 & 62 & 68 & 62 \\
\hline $\begin{array}{l}\text { Genotype with } \\
\text { highest value }\end{array}$ & 430 & 412 & 605 & 677 & 111 & 110 & 254 & 259 & 58 & 54 & 82 & 82 & 74 & 69 \\
\hline $\begin{array}{l}\text { Mean of all } \\
\text { genotypes }\end{array}$ & 291 & 299 & 577 & 658 & 106 & 104 & 222 & 226 & 48 & 46 & 69 & 71 & 70 & 65 \\
\hline
\end{tabular}

Table 2. Seed weight, and means at average harvest time $\bar{t}$ for $\ln \mathrm{W}$ and growth components of 15 tomato genotypes in Exp. 2. Averages of three NTs. Weight in $\mathrm{mg}$, leaf area in $\mathrm{cm}^{2}$ and time in days. Genotypes are ordered as done by Nieuwhof et al. (1987).

\begin{tabular}{llllllll}
\hline Genotype & $\begin{array}{l}10^{2} \text { Seed } \\
\text { weight }\end{array}$ & $10^{2} \mathrm{lnW}$ & $10^{3}$ RGR & $10^{3}$ NAR & $10^{2}$ LAR & $10^{2}$ SLA & $10^{2}$ L.WR \\
IVT-1 & 144 & $629^{*}$ & $110^{*}$ & 203 & $54^{*}$ & $82^{*}$ & 66 \\
IVT-2 & 194 & $652^{*}$ & $108^{*}$ & $259^{*}$ & 41 & 65 & 64 \\
MXXIV-13 & 207 & $640^{*}$ & 102 & $192^{*}$ & $53^{*}$ & $77^{*}$ & $69^{*}$ \\
Stupické polni & 218 & $655^{*}$ & 100 & 220 & 45 & 69 & 66 \\
Line G & 382 & $657^{*}$ & 104 & 234 & 44 & 67 & 66 \\
Line A & 309 & 675 & 105 & 220 & 48 & 73 & 65 \\
Line B & 277 & 667 & 106 & 231 & 46 & 73 & 63 \\
Radio & 274 & 664 & 103 & 232 & 44 & 69 & 65 \\
Ohio 205040 & 275 & $660^{*}$ & 104 & 217 & 47 & 70 & $69^{*}$ \\
Monita & 353 & 670 & 101 & 227 & 44 & 71 & 63 \\
Line F & 412 & $650^{*}$ & $98^{*}$ & $258^{*}$ & $38^{*}$ & $62^{*}$ & $62^{*}$ \\
Exhibition & 338 & 665 & 101 & 214 & 47 & 71 & 66 \\
Baby & 373 & 665 & 102 & 227 & 45 & 72 & 63 \\
Premier & 385 & $647^{*}$ & 100 & 231 & 43 & 69 & 63 \\
Sonatine & 337 & 677 & 104 & 228 & 45 & 71 & 65 \\
\hline
\end{tabular}

* Significantly $(P<0.05)$ different from Sonatine.

SLA with time were mostly preceded by increases in both experiments.

Of the 36 significant genotype $\times$ NT interactions found in Exp. 1 for the different growth components (mostly for LAR, SLA and LWR), 11 were confirmed in Exp. 2. Six interactions were all shown by line F. This genotype has a high seed weight, and therefore a high plant weight at the start of the experiment, but particularly at $6{ }^{\circ} \mathrm{C}$ NT low RGRs, resulting in low plant weights. The slow growth of line F genotype was accompanied by low LARs, SLAs and LWRs, also especially at $6{ }^{\circ} \mathrm{C}$ NT. 
M. NIEUWHOF, F. GARRETSEN AND J. C. VAN OEVEREN

Table 3. Effect of night temperature on growth components of tomato in Exp. 1 and Exp. 2. Means of 15 genotypes. Values at mean harvest time $\bar{t}$. Weight in $\mathrm{mg}$, leaf area in $\mathrm{cm}^{2}$, time in days.

\begin{tabular}{|c|c|c|c|c|c|c|c|c|c|c|}
\hline \multirow{2}{*}{$\begin{array}{l}\text { Night } \\
\text { temp. } \\
\left({ }^{\circ} \mathrm{C}\right)\end{array}$} & \multicolumn{2}{|l|}{ RGR } & \multicolumn{2}{|l|}{ NAR } & \multicolumn{2}{|l|}{ LAR } & \multicolumn{2}{|l|}{ SLA } & \multicolumn{2}{|l|}{ LWR } \\
\hline & Exp. 1 & Exp. 2 & Exp. 1 & Exp. 2 & Exp. 1 & Exp. 2 & Exp. 1 & Exp. 2 & Exp. 1 & Exp. 2 \\
\hline 14 & 0.12 & 0.12 & 0.22 & 0.24 & 0.54 & 0.50 & 0.80 & 0.80 & 0.67 & 0.63 \\
\hline 10 & 0.11 & 0.10 & 0.22 & 0.22 & 0.48 & 0.47 & 0.68 & 0.72 & 0.71 & 0.65 \\
\hline 6 & 0.09 & 0.09 & 0.23 & 0.23 & 0.42 & 0.39 & 0.58 & 0.58 & 0.72 & 0.67 \\
\hline
\end{tabular}

Table 4. Genotypic correlation coefficients between $\ln W$ and growth components of 15 tomato genotypes.

\begin{tabular}{rlccccc}
\hline & & RGR & NAR & LAR & SLA & LWR \\
LnW & Exp. 1 & -0.22 & +0.18 & -0.26 & -0.21 & -0.22 \\
& Exp. 2 & -0.17 & +0.22 & -0.33 & -0.28 & -0.24 \\
RGR & Exp. 1 & & +0.06 & +0.32 & +0.29 & -0.07 \\
$\cdot$ & Exp. 2 & & -0.12 & +0.45 & +0.49 & +0.20 \\
NAR & Exp. 1 & & & $-0.90^{* *}$ & $-0.89^{* *}$ & -0.29 \\
& Exp. 2 & & & $-0.93^{* *}$ & $-0.85^{* *}$ & $-0.70^{* *}$ \\
LAR & Exp. 1 & & & & $+0.96^{* *}$ & +0.29 \\
& Exp. 2 & & & & & $+0.94^{* *}$ \\
SLA & Exp. 1 & & & & +0.06 \\
& Exp. 2 & & & & & +0.40 \\
\hline
\end{tabular}

** $P<0.01$.

The other five interactions, shown by MXXIV-13 for LAR, SLA and LWR, by IVT1 for LAR and by line B for LWR, were small.

Both experiments showed strongly negative genotypic correlations between NAR and LAR and between NAR and SLA (Table 4), and Exp. 2 also showed a significant negative correlation between NAR and LWR. Both experiments showed important positive correlations between LAR and SLA, and Exp. 2 also showed a positive correlation between LAR and LWR.

Large differences in seed weight occurred between genotypes (Table 2). There were significantly positive genotypic correlations between seed weight and dry seedling weight 10 days after sowing $(+0.94)$, seed weight and $\ln W(\overline{\mathrm{t}})(+0.76)$ and seedling weight and $\ln W(\overline{\mathrm{t}})(+0.84)$.

\section{Discussion}

In many plant species, growth rate increases at higher NTs (Nieuwhof, 1987; 1988). 
This was also shown in both experiments, where RGRs increased with higher NTs. Friend \& Helson (1976), Harssema (1977) and Heuvelink (1989) also found favourable results of higher NTs on growth of young tomato plants. Higher RGRs at higher NTs were mainly due to higher SLAs, while NAR and LWR remained virtually unchanged (Harssema, 1977; Heuvelink, 1989; Exp. 1 and Exp. 2).

Decreases of RGR with time are common in most crops (e.g. Causton \& Venus, 1981), being related to decreases in NAR and/or LAR (RGR $=$ NAR $\times$ LAR $=$ NAR $\times$ SLA $\times$ LWR). In both experiments, decreases of NAR and SLA with time were only distinct at the end of the experiments, while there was a steady decrease of LWR. This agrees with results of Hurd \& Thornley (1974) and Paul et al. (1984). Decreases of RGR with time are therefore mainly due to decreases in LWR, which implies a relative increase of non-assimilating tissue. Decreases of NAR and SLA may contribute to decreases of RGR at later growth stages.

Plant weight depended strongly on seed size, as was also reported in a previous paper (Nieuwhof et al., 1989). No genotypes starting with low seedling weights had high plant weights in later growth stages.

RGR also contributes to differences in plant weight. There was little genotypic variation for RGR. Lindhout \& Pet (1990) reported considerably higher variation in RGR in 96 tomato genotypes (RGRs varied from 0.09 to $0.15 \mathrm{day}^{-1}$ ). For other crops, genotypic variation of RGR has also been measured, although genotypic differences were not always clear-cut (e.g. Brewster \& Barnes, 1981: onions; Roetman \& Sterk, 1986: Taraxacum; see also Nieuwhof et al., 1990). Differences in RGR within species are mostly small compared to those between species (Grime \& Hunt, 1975; Hunt, 1978; Poorter \& Remkes, 1990).

As RGR depends on NAR and LAR (RGR $=$ NAR $\times$ LAR), correlations between RGR and the other growth components were expected, as was indeed found in several other crops (Nieuwhof et al., 1990). In our experiments, no significant genotypic correlation occurred between RGR and the other growth components. Most genotypes with high RGRs also had high LARs, but one genotype was found with a high RGR and a low LAR but a high NAR.

The aim of this investigation was to examine the prospects of breeding tomato cultivars which are energy-efficient by producing a higher biomass. Genotypes with small seeds must be rejected as these produce seedlings and subsequently plants with a low biomass. Cultivars are required with high a RGR, these being ones with high NARs, SLAs and LWRs (RGR $=$ NAR $\times$ SLA $\times$ LWR). However, the strong negative correlation between NAR and SLA, also found in many other species (Konings, 1990; Nieuwhof et al., 1990), makes selection of these cultivars problematic. To maintain a high RGR during the whole growth period, a genotype with a low decrease in LWR with time would result in a high RGR being maintained over the whole growth period.

Genotype $\times$ NT interactions found were small. Slow or rapid growing genotypes maintained these characters irrespective of NT. Therefore in the vegetative growth stage no genotypes were present, that were better adapted to low NTs. In a separate paper results will be presented on temperature effects on growth and development of tomato plants in later growth stages. 


\section{References}

Brewster, J. L. \& A. Barnes, 1981. A comparison of relative growth rates of different individual plants and different cultivars of onion of diverse geographic origin at two temperatures and two light intensities. Journal of Applied Ecology 18: 589-604.

Causton, D. R. \& J. C. Venus, 1981. The biometry of plant growth. Arnold, London, 307 pp.

Friend, D. J. C. \& V. A. Helson, 1976. Thermoperiodic effects on the growth and photosynthesis of wheat and other plants. Botanical Gazette 137: 75-84.

Garretsen F. \& M. Keuls, 1986. Functions of time for growth characters, their evaluation and approximation to examine differences between genotypes. Euphytica 35: 11-15.

Grime, J. P. \& R. Hunt, 1975. Relative growth-rate; its range and adaptive significance in a local flora. Journal of Ecology 63: 393-422.

Harssema, H., 1977. Root temperature and growth of young tomato plants. Wageningen, 77-19: 1-85.

Heuvelink, E., 1989. Influence of day and night temperature on the growth of young tomato plants. Scientia Horticulturae 38: 11-22.

Hunt, R., 1978. Plant growth analysis. Arnold, London, 67 pp..

Hurd, R. G. \& J. H. M. Thornley, 1974. An analysis of the growth of young tomato plants in water culture at different light integrals and $\mathrm{CO}_{2}$ concentrations. Annals of Botany 38: 375-388.

Keuls, M. \& F. Garretsen, 1982. Statistical analysis of growth curves in plant breeding. Euphytica 31: 51-64.

Konings, H., 1990. Physiological and morphological differences between plants with a high NAR or a high LAR as related to environmental conditions. In: H. Lambers, M. L. Cambridge, H. Konings \& T. L. Pons (Eds.). Causes and consequences of variations in growth rate and productivity of higher plants, p. 101-123. SPB Academic Publishing, The Hague.

Lindhout, P. \& G. Pet, 1990. Effects of $\mathrm{CO}_{2}$ enrichment on young plant growth of 96 genotypes of tomato (Lycopersicon esculentum Mill.). Euphytica 51: 191-196.

Nieuwhof, M., 1987. Effects of day and night temperature on growth and development of radish (Raphanus sativus L. var. radicula Pers.) under summer conditions. Gartenbauwissenschaft 52: $72-76$.

Nieuwhof, M., 1988. Effects of day and night temperature on growth of radish (Raphanus sativus $\mathrm{L}$. var. radicula Pers.) under winter conditions. Gartenbauwissenschaft 53: 58-61.

Nieuwhof, M., F. Garretsen \& J. C. van Oeveren, 1989. Maternal and genetic effects on seed weight of tomato and effects of seed weight on growth of genotypes of tomato (Lycopersicon esculentum Mill.). Plant Breeding 102: 248-254.

Nieuwhof, M., F. Garretsen \& J. C. van Oeveren, 1990. Intervarietal variation for growth characters in tomato (Lycopersicon esculentum Mill.) grown under low light conditions at three night temperatures. CPO Report 103, Wageningen, 32 pp..

Nieuwhof, M., G. Pet \& F. Garretsen, 1987. Inheritance of characters determining growth and development of tomato (Lycopersicon esculentum Mill.) under low energy conditions. Euphytica 36: 205-213.

Paul, E. M. M., R. C. Hardwick \& P. F. Parker, 1984. Genotypic variation in the response to suboptimal temperatures of growth in tomato (Lycopersicon esculentum Mill.). New Phytologist 98 : 221-230.

Poorter, H. \& C. Remkes, 1990. Leaf area ratio and net assimilation rate of 24 wild species differing in relative growth rate. Oecologia $83: 553-559$.

Roetman, E. \& A. A. Sterk, 1986. Growth of microspecies of different sections of Taraxacum in climatic chambers. Acta Botanica Neerlandica 35: 5-22.

Smeets, L. \& F. Garretsen, 1986. Growth analyses of tomato genotypes grown under low light temperatures and low light intensity. Euphytica 35: 701-715. 